\title{
Application Research of Tethered UAV Platform in Marine Emergency Communication Network
}

\author{
Zhiqiang $\mathrm{Xu}$ \\ QingDao Jari Automation Company LTD., Shandong 266061, China \\ E-mail:260153789@qq.com
}

Received 20 November 2020; Accepted 17 December 2020;

Publication 09 March 2021

\begin{abstract}
In order to meet the needs of emergency communication for major emergency disaster rescue, a wireless emergency communication relay system based on tethered UAV platform is studied. From the perspective of practical application, the characteristics and network coverage of the emergency communication system are analyzed. The mooring UAV platform is equipped with various communication loads such as MESH (wireless grid network communication), 4G-LTE (Long term evolution fourth generation mobile communication) base station, AIS (Automatic Identification System) and so on, which are kept on the communication support ship. When the communication support ship enters the scene of maritime emergencies, the tethered UAV platform lifts off, stays for a long time and realizes the relay communication service of various carriers within a radius of tens of kilometers through its various communication payloads, which provides key communication support for the Marine emergency communication network. The actual field test of the prototype system shows that the data transmission is stable and reliable, and the short message transmission is normal, which can meet the emergency communication demand of disaster rescue.
\end{abstract}

Journal of Web Engineering, Vol. 20_2, 491-512.

doi: 10.13052/jwe1540-9589.20212

(C) 2021 River Publishers 
Keywords: Tethered UAV platform, communication support ship, command and communication ship, communication load, repeater communication, emergency communication network, MESH, AIS.

\section{Introduction}

At present, various Marine natural disasters and Marine emergencies are increasingly causing harm to Marine transportation, Marine fishery, Marine tourism and other Marine economic and production activities. In case of maritime emergencies, various rescue forces at sea fall under the jurisdiction of different regions and departments. The emergency communication capability of connectivity is insufficient, and the emergency communication support capability for maritime activities needs to be strengthened urgently.

The demand of maritime emergency communication support is reflected in the integrated emergency communication system composed of sky, air, shore, sea and potential [1]. Taking advantage of the strong load-carrying capacity of the onboard system and the capability of long-distance maneuvering and long-time stay [2], the communication support ship carries a tethered UAV platform carrying a variety of relay communication loads [3] to reach the emergency sea area quickly. It realizes all-weather, multi-functional user emergency communication access within the radius of tens of kilometers around the communication support ship [4]. In order to realize the interconnection of various rescue forces and the information communication with the shore based command center, it lays a good technical foundation for the joint cooperation of rescue work.

\section{Technical Principle of Tethered UAV Platform}

\subsection{Composition of Tethered UAV Platform}

The tethered UAV platform is mainly composed of body structure, power component, flight control component, optical communication component, light composite cable, storage device and other systems. As shown in the figure below:

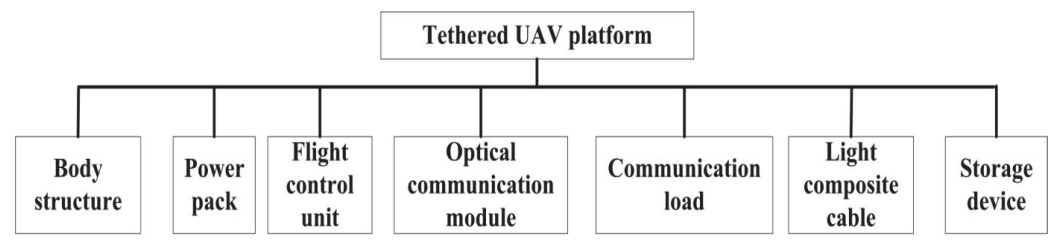

Figure 1 Composition of tethered UAV platform. 
- Body structure

The body of the tethered UAV platform adopts the conventional six rotor configuration and is made of carbon fiber composite materials. Each rotor can be quickly disassembled and assembled with the central body through the threaded structure.

- Power components

Six permanent magnet brushless motors and two blade propeller are used in the platform of the tethered UAV. When hovering, a single propeller will produce about $8 \mathrm{~kg}$ pull force.

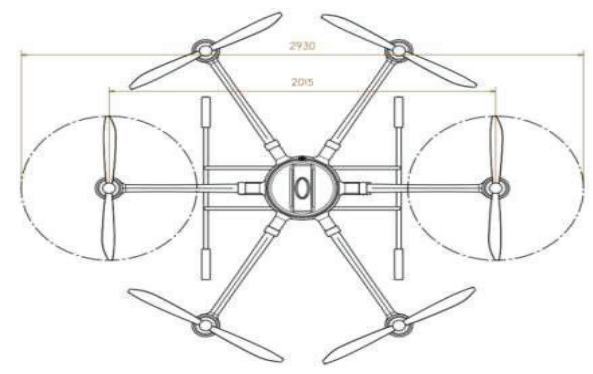

Figure 2 Outline drawing of tethered UAV platform.

\section{- Flight control components}

The control module is composed of airborne part and onboard part. The airborne part includes processor, sensor, communication link, remote control receiver and power supply; the ground part includes ground control station, winch controller, Beidou, remote control, communication link and power supply [5].

The embedded ARM processor is used in the airborne processor, which not only has powerful data computing ability, but also has rich peripheral interfaces. The sensor includes three-axis gyro, three-axis accelerometer, three-axis magnetometer, barometer, Beidou positioning component and thermometer. The three-axis gyroscope and accelerometer are inertial measuring devices, which can measure the angular velocity and linear acceleration of UAV platform, and provide platform attitude, velocity and position information through navigation operation; the three-axis magnetometer can measure the heading angle of UAV platform relative to the geomagnetic field; the barometer is used to calculate the air pressure height; the thermometer is used to measure the temperature for temperature compensation and error correction $[6,7]$. 
Arm collects sensor information such as three-axis gyroscope, threeaxis accelerometer, three-axis magnetometer, barometer, Beidou positioning component and thermometer through the built-in serial interface (SCI) and ad interface module, and collects the control signal from the remote control receiver through the built-in PWM module of the processor, and outputs the control signal of the motor governor.

The Beidou module can output platform speed and position information. In this system, the airborne Beidou module is matched with the ground Beidou module to form a dynamic differential relatively high-precision positioning Beidou module.

The communication chain includes optical communication components and wireless digital radiostation. Generally, it is wired transmission mode and communicates with the ground through optical communication components. In order to improve the reliability and security of the system, a wireless data link (digital radio station) is added as a backup communication chain [8, 9].

The remote control receiver is matched with the ground operator remote control, which is used for the UAV platform manual remote control flight.

Winch controller is matched with winch motor and connected with ground control station through serial interface [10].

The command and control component software of the tethered UAV platform includes the flight control software of the tethered UAV platform, the mission control and monitoring software of the tethered UAV platform, which mainly realizes the flight control, flight management, mission control, link monitoring, load control and other functions of the tethered UAV platform subsystem [11].

The hardware composition of command and control of UAV platform is as follows:

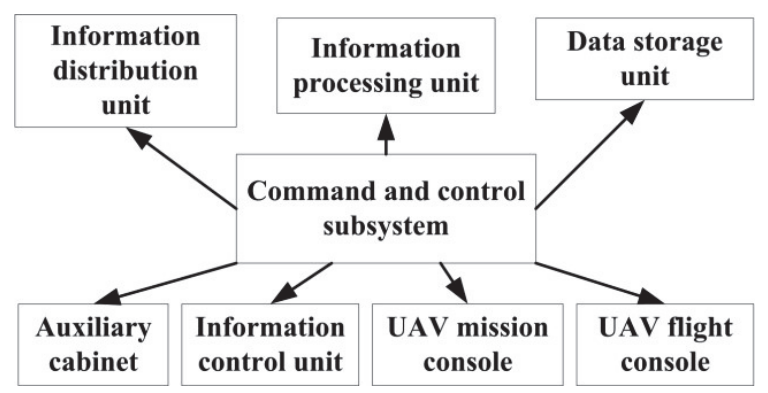

Figure 3 Command and control hardware composition of tethered UAV platform. 
The flight console and mission console of the tethered UAV platform adopt the standard general console, which is mainly composed of display unit, control unit, electronic case unit, auxiliary unit and other modules. The auxiliary cabinet is the center of data interaction in the control station, which mainly completes information access and management, system comprehensive management, work status monitoring and other functions; it mainly includes calculation unit, data exchange unit, hot backup control unit, power supply unit, work status health management unit and other parts [12].

- Optical communication components

The optical communication component transmission equipment is mainly used for the two-way high-speed communication between the tethered UAV platform and the communication support ship. The equipment adapts to the typical land and sea environment, including temperature, wind speed, etc., and has the requirements of wind resistance, salt fog resistance, corrosion resistance, etc., so as to ensure the high reliability operation in various harsh environments, and ensure the convenient installation without any optical or electrical adjustment.

The device has a standard data transmission channel of video transmission, Ethernet, audio, RS232 on a single optical fiber, and adopts plug and play technology for quick installation.

\section{- Communication load}

The communication load of tethered UAV platform includes tethered airborne lightweight mesh equipment, 4G-LTE base station equipment and AIS receiver [13-17].

\section{(1) Tether onboard MESH equipment}

The communication load of the tethered UAV platform is equipped with MESH self networking relay station and $5 \mathrm{dBi}$ omnidirectional antenna, with total power less than $30 \mathrm{~W}$ and total weight less than $3 \mathrm{~kg}$. The ship is equipped with a base station with a size of $2 \mathrm{U}$ and a power consumption of less than $60 \mathrm{~W}$. The main characteristics of MESH broadband wireless adhoc network communication equipment are as follows:

- Strong diffraction ability: the radio frequency works in the lowfrequency band, has good diffraction ability, and can work in the non line of sight environment; 
- Anti multipath: Using such as LTE modulation technology which can resist the ocean multipath environment well;

- Support high-speed movement: It adapts to the work requirements in the high-speed moving environment such as airborne and onboard;

- Wide coverage: When the network is expanded, a regional wireless transmission network will be formed by self-organization, and the network capacity will reach 120 Mbps.

- No center networking: The system can realize network synchronization without external

- Timing of Beidou, independent of existing infrastructure;

- Good invulnerability, It han strong network robustness and strong selfhealing ability;

- Mobile communication: The equipment can communicate in real time in the mobile, and the routing algorithm of ad hoc network ensures to select the optimal information transmission path in real time in the equipment;

- Any IP wireless device with WiFi and Bluetooth functions can be accessed;

- Supporting digital equipment access with standard 10/100 M Ethernet port.

(2) Tethered airborne 4G-LTE equipment

Tethered airborne 4G-LTE equipment mainly provides broadband access, voice, text, image and other multimedia communication services for maritime emergency users, which is used to achieve wireless communication coverage in emergency sea areas. It is compatible with the access of mobile operator network and civil LTE terminal, and can realize the business intercommunication with the operator network, and can carry out the access of marine local area and multimedia service according to the actual needs. At the same time, when the communication link with the shore base fails, it can also use the local LTE system to operate in the island mode, and still can play a certain role in the field emergency communication. In addition, it supports NB IOT to provide information access services for all kinds of offshore unmanned detection platforms in the emergency sea area and collect sensing data.

The purpose of tethering airborne 4G-LTE wireless base station is to cope with the wireless network coverage within several kilometers or even more than ten kilometers around the ship. Its purpose is to deal with emergencies on the sea, law enforcement personnel and the rescued personnel 
can communicate voice and data through ordinary mobile terminals, so that everyone can keep in touch with each other and facilitate communication and coordination. At the same time, considering the difference of LTE network system of three domestic mobile operators, the shipboard communication terminal is equipped with two sets of base station equipment, FDD-LTE and TDD-LTE. Frequency interval measures are taken between them to avoid the interference of cell signals between adjacent frequencies. The two sets of wireless networks share one set of core network equipment, which saves the installation space of equipment and is also convenient for operation and management. In addition, TDD-LTE integrates NB-IOT narrowband Internet of things function, and carries out remote operation and management of some intelligent equipment on the onboard system through NB-IOT wireless signal, so as to realize unattended control. In addition, due to the maturity of spectrum resources and communication system technology, LTE in the public network can realize the high-speed transmission of uplink and downlink data within its effective coverage. It can not only maintain the traditional voice communication, but also realize the collection and transmission of on-site audio and video data. It can also access the Internet business, and the construction cost is relatively low [18].

\section{(3) Tethered airborne AIS}

The captive airborne AIS can receive the AIS information sent by civil ships and receive the time, location message, the timely system signal, the working mode setting information and the status inquiry information, etc. of the receiving platform. After receiving the AIS signal sent by civil ships, the antenna will send the intermediate frequency signal to the signal processing module after receiving, filtering, amplification and mixing by the Radio frequency receiving module. The signal processing module completes signal sampling, synchronization, decoding and calibration, etc., and forms AIS message, which is then analyzed, processed and converted into target attribute identification information such as distance, bearing information, speed and type of the relative platform to form the target information message, which is then output to the communication support ship through the $1553 \mathrm{~B}$ interface.

The tethered airborne AIS receiver mainly consists of two parts: host and antenna. The host is mainly divided into RF receiving module, signal 
processing module and interface management module. The composition block diagram of the equipment is shown in the figure below.

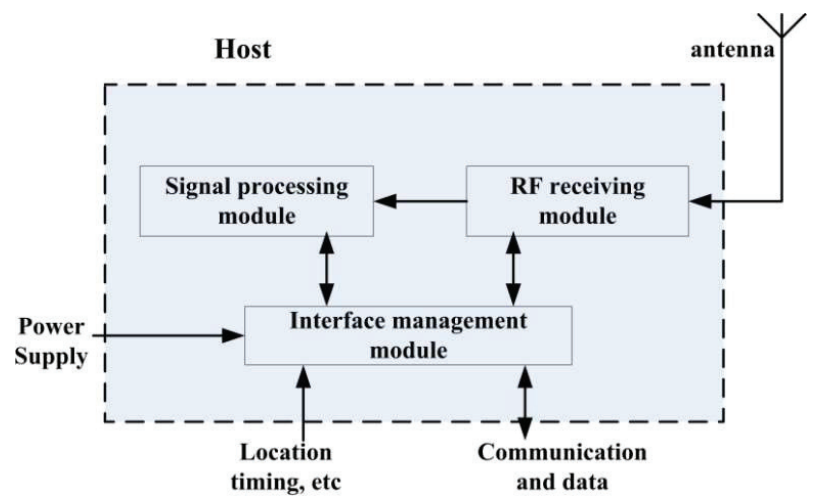

Figure 4 Block diagram of airborne AIS receiving equipment.

- Light composite cable

The ultralight photoelectric composite cable is mainly used for the connection between the tethered UAV platform and the communication ship. The composite cable can adapt to the typical sea environment, including temperature, wind speed, etc. It meets the requirements of wind resistance, salt fog resistance, corrosion resistance, etc. Its wind resistance is grade 8 .

The cable has super light unit weight and good mechanical and physical properties, including two electrical units and one optical unit. The electrical unit adopts conductor and insulating materials with excellent performance, and the optical unit adopts single-mode optical fiber. The total amount of the whole cable is light and the performance is stable, which can meet the repeated use requirements. The optical unit adopts tight package structure to ensure the structural performance of the cable is stable when it is used repeatedly.

- Collection device of UAV platform

(1) It is used for daily storage of UAV platform, providing protection for UAV platform and isolating from bad environment. It can be moisture proof, waterproof and dustproof. The UAV platform is fixed in the storage warehouse to prevent shaking and provide a reliable mooring method for the UAV platform.

(2) Provide take-off and landing platforms for uav platforms. The storage device comprises an elevatable take-off and landing platform, 
which is used to lift the UAV platform away from the storage device and serve as the take-off and landing platform of uav platform.

(3) On the supply of long-distance power for uav platform. The storage device provides the required power for the UAV platform through cables, and the cable length ensures that the uav platform can cruise at a height of more than 100 meters.

(4) Retracting and releasing UAV platform. The electric winch is placed in the receiving device, and the cable is rewound and released through the program control of the electric winch, and the uav platform flight height is controlled in real time by receiving the electric winch control instruction provided by the outside. In case of emergency, it has power off function.

(5) It can be firmly installed with vehicles and communicate with electrical and communication interfaces. Provide cable leakage, open circuit and short circuit alarm.

\subsection{Tethered UAV Platform Function}

According to the construction mission of the maritime emergency communication test system, the tethered UAV platform is mainly to realize the function of rapid recovery and enhancement of communication. It takes advantage of the characteristics of the tethered UAV platform, such as fast deployment speed, long endurance, etc., to carry the business terminal to the task execution area with the carrier to form a fast communication network [19].

Tethered UAV platform is mainly used as the carrier platform of business terminal, providing power and information transmission path for business loads such as MESH and AIS, and realizing emergency communication support capability within $100 \mathrm{~km}$ around the UAV platform through certain altitude. The main functions are as follows:

- Providing the functions of rapid network construction, network supplement and strong network for emergency response of maritime emergencies;

- Providing the interconnection function with the existing network;

- Providing emergency communication access function of offshore MESH, 4G-LTE and AIS;

- Having vertical take-off, landing and long-term fixed-point hover flight functions;

- Having the following flight function by accompany of vessel; 
- Having the function of receiving and releasing UAV platform and tethered cable according to the instructions;

- Having automatic folding and storage functions of UAV platform.

\subsection{Interface Relationship}

Tethered UAV platform is mainly used as the carrier platform of relay communication link, providing power for MESH, 4G-LTE, AIS and other communication loads. It receives mission information from mission load, commands and controls components to send remote control information to UAV platform and receive telemetry information and mission load information.

\section{(1) Internal interface}

Tethered UAV platform subsystem is mainly used as the carrier platform of business terminal, which provides power for LTE and AIS business loads, and receives mission information from mission loads. Tethered support subsystem provides power for UAV platform subsystem and command and control subsystem, and provides physical channel for information transmission between them. Command and control subsystem sends remote control information to UAV platform subsystem and receives telemetry information and mission load information.

Internal interface relationship table of tethered UAV platform subsystem:

\begin{tabular}{|c|c|c|c|c|c|}
\hline NO & $\begin{array}{l}\text { Interface } \\
\text { Name }\end{array}$ & Source & Lodging & Interface Form & Information Elements \\
\hline 1. & $\begin{array}{l}\text { Remote } \\
\text { control } \\
\text { information of } \\
\text { UAV platform }\end{array}$ & $\begin{array}{l}\text { Command and } \\
\text { control } \\
\text { subsystem } \\
\text { (flight } \\
\text { console) }\end{array}$ & $\begin{array}{l}\text { Unmanned } \\
\text { platform } \\
\text { subsystem } \\
\text { (flight control } \\
\text { equipment) }\end{array}$ & $\begin{array}{l}\text { RS232 } \\
\text { (Optical fiber) }\end{array}$ & $\begin{array}{l}\text { Unmanned platform } \\
\text { control command } \\
\text { (take-off, landing, } \\
\text { altitude setting) }\end{array}$ \\
\hline 2. & $\begin{array}{l}\text { Remote } \\
\text { control } \\
\text { information of } \\
\text { mission load }\end{array}$ & $\begin{array}{l}\text { Command and } \\
\text { control } \\
\text { subsystem } \\
\text { (mission } \\
\text { control } \\
\text { station) }\end{array}$ & $\begin{array}{l}\text { Unmanned } \\
\text { platform } \\
\text { subsystem } \\
\text { (mission } \\
\text { payload) }\end{array}$ & $\begin{array}{l}\text { RS232/422 } \\
\text { (Optical fiber) }\end{array}$ & $\begin{array}{l}\text { Mission load control } \\
\text { command (power off } \\
\text { and parameter setting) }\end{array}$ \\
\hline 3. & $\begin{array}{l}\text { Telemetry } \\
\text { information }\end{array}$ & $\begin{array}{l}\text { Unmanned } \\
\text { platform } \\
\text { subsystem }\end{array}$ & $\begin{array}{l}\text { Command and } \\
\text { control } \\
\text { subsystem } \\
\text { (control } \\
\text { station) }\end{array}$ & $\begin{array}{l}\text { RS232/422 } \\
\text { (Optical fiber) }\end{array}$ & $\begin{array}{l}\text { Unmanned platform } \\
\text { status information and } \\
\text { mission load status } \\
\text { information }\end{array}$ \\
\hline 4. & $\begin{array}{l}\text { Task } \\
\text { information }\end{array}$ & Mission load & $\begin{array}{l}\text { Command and } \\
\text { control } \\
\text { subsystem }\end{array}$ & $\begin{array}{l}\text { network } \\
\text { (Optical fiber) }\end{array}$ & user data \\
\hline
\end{tabular}


(2) External interface

The external interface of tethered UAV platform subsystem mainly includs power supply interface and information interface.

External interface relationship table of tethered UAV platform subsystem:

\begin{tabular}{|c|c|c|c|c|c|}
\hline NO & $\begin{array}{l}\text { Interface } \\
\text { Name }\end{array}$ & Source & Lodging & Interface Form & Information Elements \\
\hline 1. & $\begin{array}{l}\text { Status } \\
\text { information }\end{array}$ & $\begin{array}{l}\text { Tethered UAV } \\
\text { platform } \\
\text { subsystem }\end{array}$ & $\begin{array}{l}\text { Shipboard } \\
\text { communication } \\
\text { subsystem }\end{array}$ & Optical fiber & $\begin{array}{l}\text { UAV platform } \\
\text { subsystem status } \\
\text { information }\end{array}$ \\
\hline 2. & $\begin{array}{l}\text { Business } \\
\text { information }\end{array}$ & $\begin{array}{l}\text { Tethered UAV } \\
\text { platform } \\
\text { subsystem }\end{array}$ & $\begin{array}{l}\text { Shipboard } \\
\text { communication } \\
\text { subsystem }\end{array}$ & Optical fiber & User business data \\
\hline 3. & $\begin{array}{l}\text { Accusation } \\
\text { information }\end{array}$ & $\begin{array}{l}\text { Shipboard } \\
\text { communication } \\
\text { subsystem }\end{array}$ & $\begin{array}{l}\text { Tethered UAV } \\
\text { platform subsystem }\end{array}$ & Optical fiber & $\begin{array}{l}\text { UAV platform task } \\
\text { scheduling command } \\
\text { information }\end{array}$ \\
\hline 4. & $\begin{array}{l}\text { Meteorological } \\
\text { information }\end{array}$ & $\begin{array}{l}\text { Support vessel } \\
\text { subsystem }\end{array}$ & $\begin{array}{l}\text { Tethered UAV } \\
\text { platform subsystem }\end{array}$ & network & $\begin{array}{l}\text { Wind direction, wind } \\
\text { speed, precipitation, } \\
\text { temperature, etc }\end{array}$ \\
\hline 5. & $\begin{array}{l}\text { Power } \\
\text { interface }\end{array}$ & $\begin{array}{l}\text { Support vessel } \\
\text { subsystem }\end{array}$ & $\begin{array}{l}\text { Tethered UAV } \\
\text { platform subsystem }\end{array}$ & power supply & $220 \mathrm{~V}$ AC $30 \mathrm{KW}$ \\
\hline
\end{tabular}

\section{Application of Tethered UAV Platform in Marine Emergency Communication System}

\subsection{Composition of Marine Emergency Communication System}

The composition of the marine emergency communication system is shown in the following figure:

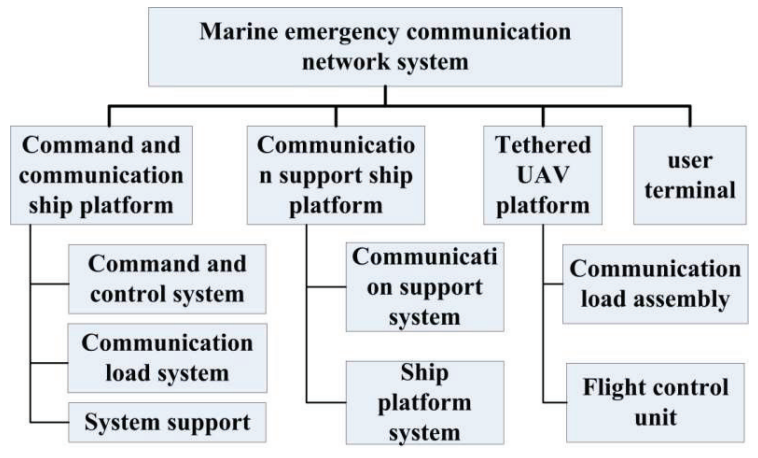

Figure 5 Composition of marine emergency communication network system. 
Maritime emergency communication networking system includes command communication ship platform, communication support ship platform, user terminal and mooring UAV platform. In non-emergency period, the maritime emergency communication networking system can realize shortterm or regular mobile communication service and provide the carrying function of conventional transport ship [20].

The maritime emergency communication networking system can develop adaptive emergency communication solutions for a variety of maritime emergency task scenarios. Through the rapid deployment of communication support ship, it can realize communication capacity enhancement, regional network replenishment, regional coverage, information returning to shore and other capabilities, as well as realize material connection, command and dispatch and other functions [21].

The details are as follows:

- Wireless communication coverage of marine area: Using MESH technology for wireless communication coverage in emergency marine area, establishing mobile communication emergency network, and providing multimedia communication services for emergency marine area.

- Internet access based on shore: it can be realized by satellite communication link and microwave line of sight communication equipment. When the broadband link connecting the shore based center fails, the ship's MESH equipment and 4G-LTE equipment can make the local base station operate in the island mode, still cover the sea area, and ensure the emergency communication on site.

- Perception data collection: provide information access services to all kinds of offshore unmanned detection platforms in emergency sea areas by using large area narrow band wireless access technology.

- Multi media dispatching of emergency operation in the emergency sea area: it can be used as the temporary command and dispatching center on board to conduct the command and dispatching of emergency operation information communication.

- The SOS signal search function based on AIS .

- Use of the tethered UAV platform which is lifted off highly to make the sea area wireless coverage stronger and the coverage larger.

\subsection{System Information Interface}

The information interface of emergency communication networking system is shown in the figure below: 


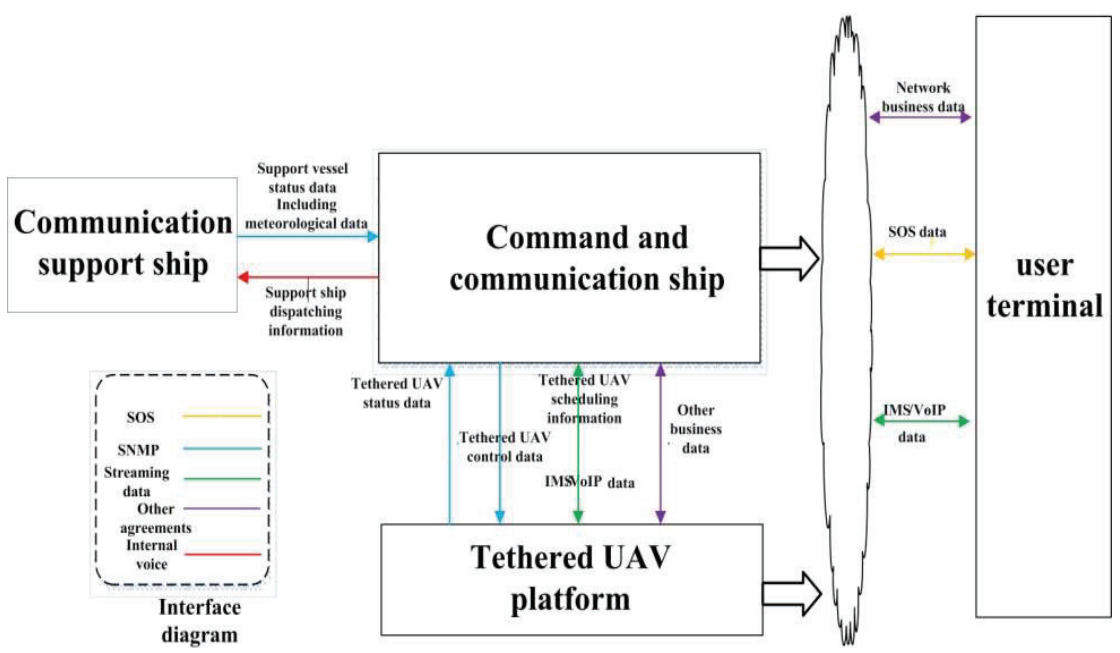

Figure 6 Internal information interface of emergency communication networking system.

\subsection{Tethered UAV Achieves Greater Communication Coverage in the Maritime Emergency Communication System}

In the relay communication system of tethered UAV, the performance of airborne center station antenna and ground terminal antenna is an important factor affecting the coverage and quality of relay communication. As a communication relay node, tethered unmanned aerial vehicle (UAV) flies with the lift off center station as a communication relay node, and forms a communication network after networking with various user terminals on the ground. Therefore, its antenna beam must be able to cover all ground terminals within the networking range, and it is better to make the air transmitted signals have equal gain distribution in the whole coverage area [22].

Therefore, the airborne antenna needs to choose omni-directional antenna, because the omni-directional antenna can receive signals from all angles in the horizontal direction, and can also radiate signals to all angles, and the energy radiated at each angle is basically equal.

The omnidirectional antenna with a gain of $3 \mathrm{dBi}$ is used in this system. The ground terminal antenna can use directional antenna with good directivity, high gain, long transmission distance and strong anti-jamming ability to make up for the shortcomings of low power of airborne communication equipment and low gain of omni-directional antenna, so as to improve the 
efficiency of the whole relay communication system. Considering the portability and operability of the ground terminal, omnidirectional antenna is used in the user terminal of the system [23].

Wireless communication relay system involves many advanced mobile communication technologies, including orthogonal frequency division multiplexing (OFDMA), adaptive modulation and demodulation technology, intelligent multiple antenna technology (MIMO), beamforming technology, distributed transmission and hierarchical receiving technology, adaptive retransmission mechanism (HARQ), automatic transmission power control technology, etc.

For radio signals transmitted in free space, the received signal strength can be calculated by formula (1):

$$
\left\{\begin{array}{c}
\mathrm{P}_{\mathrm{r}}=\mathrm{P}_{\mathrm{t}} \frac{\mathrm{G}_{\mathrm{t}} \mathrm{G}_{\mathrm{r}} \lambda^{2}}{(4 \pi)^{2} \mathrm{~d}^{2} \Delta \mathrm{L}} \\
\Delta \mathrm{L}=32.44+20 \lg \mathrm{d}+20 \lg \mathrm{F}
\end{array}\right.
$$

$\mathrm{P}_{\mathrm{r}}$ and $\mathrm{P}_{\mathrm{t}}$ are the power of the receiver and transmitter, $\lambda$ is the transmitting wavelength, $G_{r}$ and $G_{t}$ are the antenna gain of the receiver and transmitter respectively, $\Delta \mathrm{L}$ is the free space loss, $\mathrm{F}$ is the system operating frequency and $\mathrm{d}$ is the communication distance. The coverage distance of wireless communication relay system can be calculated by formula (2):

$$
r=\sqrt{\frac{R\left(\frac{P_{t} G_{t} G_{r} \lambda^{2}}{16 \pi^{2} \Delta L K R_{b} T \gamma_{0}}-H^{2}\right)}{R+H}}
$$

Where $\mathrm{R}$ is the radius of the earth, $\mathrm{H}$ is the lift off height of the central station, $\mathrm{K}$ is the Boltzmann constant, $\mathrm{T}$ is the equivalent noise temperature at the receiver, $\gamma_{0}$ is the minimum SNR threshold at the receiver, and $\mathbf{R}_{\mathrm{b}}$ is the rate of information transmission.

In the mobile communication relay system model of tethered UAV platform, the communication performance is closely related to the size of mission area and system network coverage. The distance between the ground base station and the center of the mission area served by the tethered UAV platform and the radius of the mission area will affect the communication performance of the system. When the distance between the ground base station and the center of the mission area is larger, the signal transmission link is longer. According to Equation (1), the received signal power becomes smaller. 
When the received signal power becomes smaller, the signal-to-noise ratio will be reduced. When the signal-to-noise ratio changes, the link rate also changes.

According to formula (2), the information transmission rate is strongly affected by the change of the launch position of the tethered UAV, the SNR threshold of the received signal and the size of the system network coverage. It is worth noting that the influence of some obstacles will make the signal attenuation, resulting in the signal-to-noise ratio becoming smaller. Therefore, in the long-distance data transmission scenario, the communication throughput is related to the transmission distance and the impact of obstacles.

\subsubsection{AIS system coverage of conventional maritime emergency communication network}

If we assume that the altitude of communication ship antenna is $10 \mathrm{~m}$ high and the uav flight altitude is $200 \mathrm{~m}$ high and follow the general AIS device performance configuration, the maximum communication distance between the two is as follows:

$$
d=2.5 \times(\sqrt{\mathrm{H}(\mathrm{m})}+\sqrt{\mathrm{h}(\mathrm{m})})=2.5 \times(\sqrt{20}+\sqrt{200})=46.54 \mathrm{~km}
$$

Considering the space loss and the state of the UAV's high-speed flight, the effective communication distance between them is about $38 \mathrm{~km}$ which is the results of actual measurement. Due to the limited height of communication antennas of carriers such as floating unmanned platform and unmanned boat, the communication distance between them and the communication ship is about $3 \sim 5 \mathrm{~km}$. Communication distance between communication command ship and communication support ship is:

$$
d=2.5 \times(\sqrt{\mathrm{H}(\mathrm{m})}+\sqrt{\mathrm{h}(\mathrm{m})})=2.5 \times(\sqrt{20}+\sqrt{20})=22.36 \mathrm{~km}
$$

We measured the communication distance which is in $17 \mathrm{~km}$ or so.

Communication distance between shore-based command Center (antenna height $50 \mathrm{~m}$ ) and communication ship (antenna height $10 \mathrm{~m}$ ):

$$
d=2.5 \times(\sqrt{\mathrm{H}(\mathrm{m})}+\sqrt{\mathrm{h}(\mathrm{m})})=2.5 \times(\sqrt{200}+\sqrt{20})=46.54 \mathrm{~km}
$$


We measured the communication distance which is in $40 \mathrm{~km}$ or so. As shown in the figure below:

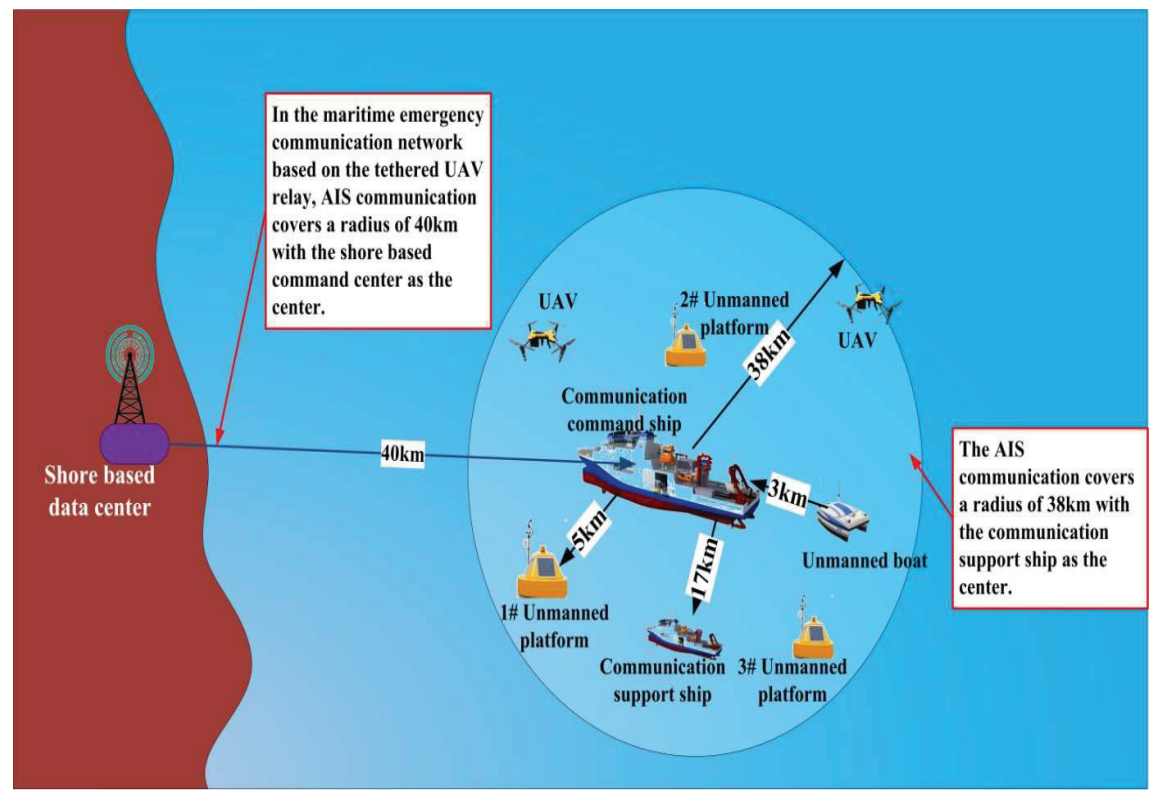

Figure 7 AIS communication coverage diagram for conventional maritime emergency communication networking.

\subsubsection{AIS system coverage of maritime emergency communication network based on communication relay of tethered UAV}

If we assume that the communication ship keeps the UAV antenna at a height of $120 \mathrm{~m}$ and the remote UAV flies at a height of $200 \mathrm{~m}$ and follow the general AIS device performance configuration, the maximum communication distance between the two is:

$$
d=2.5 \times(\sqrt{\mathrm{H}(\mathrm{m})}+\sqrt{\mathrm{h}(\mathrm{m})})=2.5 \times(\sqrt{120}+\sqrt{200})=62.74 \mathrm{~km}
$$

Considering the space loss and the state of the UAV's high-speed flight, the effective communication distance between the two is about $60 \mathrm{~km}$ after the actual measurement. Due to the limited height of communication antennas of carriers such as floating unmanned platform and unmanned boat, the communication distance between them and the communication support ship is 
about $5 \sim 10 \mathrm{~km}$. Communication distance between communication command ship and communication support ship:

$$
d=2.5 \times(\sqrt{\mathrm{H}(\mathrm{m})}+\sqrt{\mathrm{h}(\mathrm{m})})=2.5 \times(\sqrt{120}+\sqrt{20})=38.55 \mathrm{~km}
$$

We measured the communication distance which is in $36 \mathrm{~km}$ or so.

Communication distance between shore-based command center and communication ship:

$$
d=2.5 \times(\sqrt{\mathrm{H}(\mathrm{m})}+\sqrt{\mathrm{h}(\mathrm{m})})=2.5 \times(\sqrt{200}+\sqrt{120})=60.6 \mathrm{~km}
$$

We measured the communication distance which is in $58 \mathrm{~km}$ or so. As shown in the figure below:

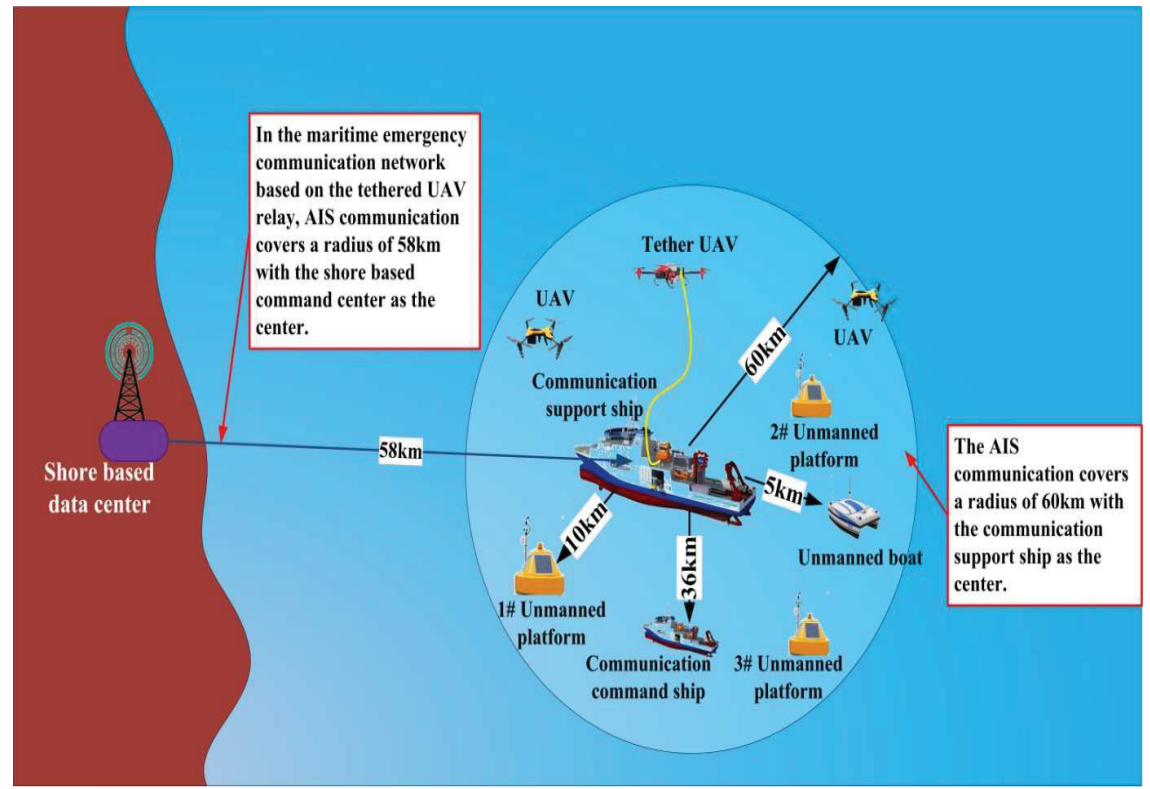

Figure 8 AIS communication coverage diagram of maritime emergency communication network based on relay communication of tethered UAV.

Through the above analysis, we can see that the communication distance has more than doubled from communication support ship to distal $\mathrm{UAV}$, the boat, unmanned platform based on the mooring platform drones in the maritime emergency communication network. The two-way broadband communication distance from the communication ship to the shore 
based command center has also increased by more than $50 \%$. We can see that mooring UAV platforms at sea emergency communication network has played a key communication relay function, it makes the maritime emergency communication network coverage increased considerably. At the same time we also realized the connectivity and working together between the various carrier.

\section{Conclusion}

When natural disasters occur suddenly, the original public communication network facilities are basically destroyed. It is necessary to quickly establish a temporary emergency communication network to ensure the smooth development of emergency rescue work.

The wireless emergency communication relay system based on tethered unmanned platform has the advantages of rapid and flexible deployment, long space time and free from the restrictions of complex terrain and features. It can meet the needs of voice, image and video, data, short message and other transmission services in emergency rescue communication, and can play an important role in emergency rescue.

However, the air relay communication equipment is restricted by the carrying capacity of UAV platform, which puts forward higher requirements for relay communication equipment in terms of volume, weight and power consumption. At the same time, the meteorological environment at the emergency rescue site is generally bad, and the relay communication equipment and the tethered unmanned platform also need to be strengthened in terms of rain and wind resistance, dust and mildew prevention.

The tethered UAV platform plays a key role of communication relay in the maritime emergency communication networking system, which provides a wide range of communication coverage for the maritime emergency communication networking system, builds a key communication bridge for various carriers to achieve interconnection and interworking, and plays an important role in the process of handling the emergency maritime events.

\section{References}

[1] Huayu Shen, Yun Jia. Research on emergency communication of sudden disaster [J], science and technology information, 2010, 18. 
[2] Bin Wu, Liang Wu. Current situation and development of overseas maritime wireless communication [J]. Naval electronic engineering, 2008, 04(28): 18-21.

[3] Wenkai Gu, Dahua Wang. Major application of airship emergency communication system in disaster relief $[\mathrm{J}]$, ship electronic engineering, tenth issue, 2014.

[4] Rumei Liu, Bo Yang, Guangming Tang, etc. Integrated emergency communication system solutions [J], communication technology, (2013) 04-064-03.

[5] Magnus J. Harrold, Philipp R. Thies, David Newsam, Claudio Bittencourt Ferreira, Lars Johanning. Large-scale testing of a hydraulic non-linear mooring system for floating offshore wind turbines, Ocean Engineering, 2020-06-15.

[6] Ringsberg Jonas W., Jansson Hanna, Örgård Martin, Yang Shun Han, Johnson Erland. Design of Mooring Solutions and Array Systems for Point Absorbing Wave Energy Devices - Methodology and Application, Journal of Offshore Mechanics and Arctic Engineering, 2020-06-01.

[7] C.L.G. Oikonomou, R.P.F. Gomes, L.M.C. Gato, A.F.O. Falcão. On the dynamics of an array of spar-buoy oscillating water column devices with inter-body mooring connections, Renewable Energy, 2020-04-15.

[8] P.K. Stansby, E. Carpintero. Moreno. Hydrodynamics of the multifloat wave energy converter M4 with slack moorings: Time domain linear diffraction-radiation modelling with mean force and experimental comparison, Applied Ocean Research, 2020-04-02.

[9] Sergej Antonello Sirigu, Mauro Bonfanti, Ermina Begovic, Carlo Bertorello, Panagiotis Dafnakis. Experimental Investigation of the Mooring System of a Wave Energy Converter in Operating and Extreme Wave Conditions, Journal of Marine Science and Engineering, 2020-03-07.

[10] Xianxi Jin, Zhenwan Jin, Zegen Nan. Design of sliding mode control system for automatic mooring devices for vessels, Journal of the Korean Society of Marine Engineering, 2019-11-30.

[11] Wubin Zhu, Li Zhou, Zhang Yi, Li Jinjin, Qi Jing, etc. Research on Key Technologies of UAV based maritime cooperative search and rescue [J], modern information technology, Vol. 3, No. 13, 2019.

[12] Qiang Chen, Xiaopeng Yang, Dong Yang, Juan Ni, et al. Research progress of low altitude wireless channel modeling and equalization technology [J]. Telecommunication technology, 2012:01(52): 117-124. 
[13] Guokun Qi. Research on application of wireless communication technology between UAV and sea buoy [C], Hebei University of technology, 2014.

[14] Ru Zhang. Application of AIS in maritime search and rescue [J], China water transport, September 2019, Vol. 10, No. 9.

[15] Yong Bai, Wencai Du, et al. Research on maritime ship communication using wireless and heterogeneous networks [C], School of information science and technology, Hainan University, 2013.

[16] Saqib Ejaz, Feng-Fan Yang, Hongjun Xu. Split labeling diversity for wireless half-duplex relay assisted cooperative communication systems, Telecommunication Systems, 2020-07-13.

[17] Jongyun Kim, Pawel Ladosz, Hyondong Oh. Optimal communication relay positioning in mobile multi-node networks, Robotics and Autonomous Systems, 2020-07-03.

[18] Salman Goli-Bidgoli, Naser Movahhedinia. Towards Ensuring Reliability of Vehicular Ad Hoc Networks Using a Relay Selection Techniques and D2D Communications in 5G Networks, Wireless Personal Communications, 2020-06-18.

[19] Mohammadreza Tarihi, Mohammad Mahdinejad Noori, Mohammadhossein Madani. Improving the Performance of HALE UAV Communication Link Through MIMO Cooperative Relay Strategy, Wireless Personal Communications, 2020-05-12.

[20] Dalal Abdulmohsin Hammood, Abdulmohsin Hammood Dalal, Alkhayyat Ahmed. Relay Sensors Selection in Wireless Communication: Bit Error Rate Analysis, IOP Conference Series: Materials Science and Engineering, 2020-05-01.

[21] Fadhil Sahib Hasan. Design and Analysis of Three-Way Relay Network Coding Schemes Based Differential Chaos Shift Keying Communication System, Wireless Personal Communications, 2020-04-13.

[22] Kanithan S., Vignesh N. Arun, Karthikeyan E., Kumareshan N. An intelligent energy efficient cooperative MIMO-AF multi-hop and relay based communications for Unmanned Aerial Vehicles (UAVs networks), Computer Communications, 2020-01-21.

[23] Omer Cetin, Ibrahim Zagli. Continuous Airborne Communication Relay Approach Using Unmanned Aerial Vehicles, Journal of Intelligent \& Robotic Systems, 2012-01-15. 


\section{Biography}

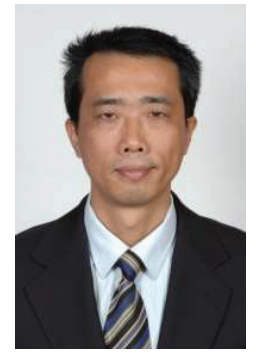

Zhiqiang $\mathbf{X u}$ is a senior engineer and technical director of Qingdao JARI Automation Co., Ltd. of China shipbuilding group. His research fields include marine informatization and communication navigation engineering. His innovative research and pioneering work in the field of Beidou based air sea three-dimensional positioning navigation and emergency search and rescue system has won the first class of satellite navigation technology progress of China satellite positioning and navigation Association in 2020 Awards. The paper "Research on multi mode fusion wireless communication technology in marine emergency command mobile networking system" was published in global positioning system (GPS), Vol. 45, No. 4, August 2020. 
